$$
\text { CONF-9011178--1 }
$$

UCRL-JC- 104730

PREPRINT

$$
\begin{aligned}
& \text { Rergival } \\
& \text { FEB } 061991
\end{aligned}
$$

\title{
SENSITIVITY OF STRATOSPHERIC OZONE TO PRESENT AND POSSIBLE FUTURE AIRCRAFT EMISSIONS
}

\author{
Donald J. Wuebbles
}

Douglas E. Kinnison

This paper was prepared for submitta. to German Aerospace Reseurch Establishment (DLR)

Seminar on Air Traffic and the Environment Bonn, FGR, November 15-16, 1990.

August 1800

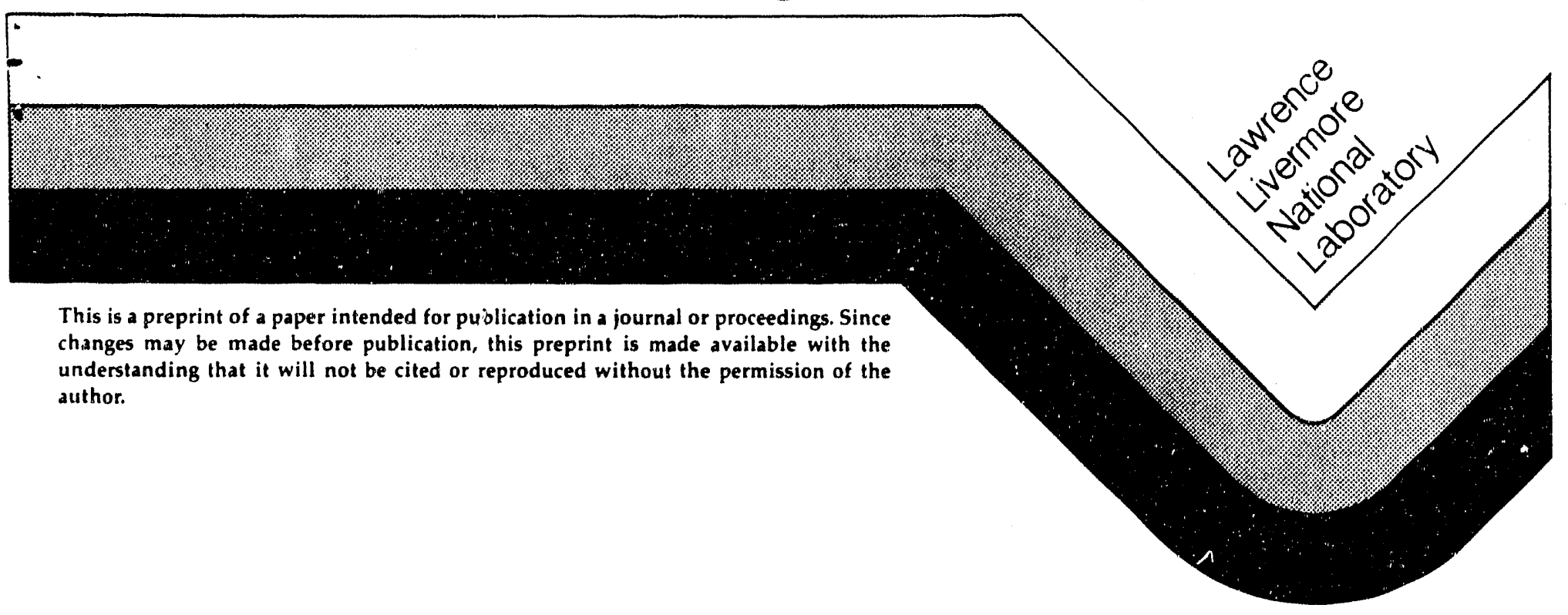


This document was prepared as an account of work spomsored by an agency of the United States Government. Neither the United States Government nor the University of California nor any of their employeex, makes any warranty, express or implied, or assumes any lezal liability of responsibility for the accuracy, completeness, or usefutness of any information, apparatus, product, or process disclosed, or represents that its use would not infringe privately owned rights. Reference herein to any specific commercial products, process, or service by trade name, trademark, manufacturer, or otherwise, does not necessarily constitute or imply its endorsement, recominendation. or favoring by the United States Government or the Univenity of California. The views and opinions of authon expreased berein do not necesuarily state or reflect those of the Unbied States Governasent or the University of Californich, and shall not be used for advertising or product endorsemeat purposes. 


\title{
SENSITIVITY OF STRATOSPHERIC OZONE TO PRESENT AND POSSIBLE FUTURE AIRCRAFT EMISSIONS
}

\author{
Donald J. Wuebbles and Douglas E. Kinnison \\ Atmospheric and Geophysical Sciences Division \\ Lawrence Livermore National Laboratory \\ Livermore, CA 94550 \\ UCRL-JC--104730 \\ DE91 007140
}

\begin{abstract}
The aircraft industry is showing renewed interest in the development of supersonic, high flying aircraft for intercontinental passenger flights. There appears to be confidence that such highspeed civil transports can be designed, and that these aircraft will be economically viable as long as they are also environmentally acceptable. As such, it is important to establish the potential for such environmental problems early in the aircraft design. Initial studies with LLNL models of global atmospheric chemical, radiative, and transport processes have indicated that substantial decreases in stratospheric ozone concentrations could result from emissions of $\mathrm{NO}_{\mathbf{x}}$ from aircraft flying in the stratosphere, depending on the fleet size and magnitude of the engine emissions. The purpose of this study is to build on previous analyses of potential aircraft emission effects on ozone in order to better define the sensitivity of ozone to such emissions. In addition to $\mathrm{NO}_{\mathbf{x}}$, the effects of potential emissions of carbon monoxide and water vapor are also examined. More realistic scenarios for the emissions as a function of altitude, latitude, and season are examined in comparison to prior analyses. These studies indicate that the effects on ozone are sensitive to the altitude and latitude, as well as the magnitude, of the emissions.
\end{abstract}

\section{INTRODUCTION}

The first research studies of the potential environmental impacts from commercial fleets of aircraft flying in the stratosphere were done in the early 1970s (Harrison,1970; Johnston, 1971). These studies suggested that the emissions from fleets of such aircraft could cause a significant reduction in the concentrations of ozone in the stratosphere, with accompanying increases in the amount of ultraviolet radiation reaching the Earth's surface. The primary concern, as pointed out by Johnston, was the chemical destruction of ozone from emissions of nitrogen oxides $\left(\mathrm{NO}_{\mathbf{x}}\right)$ produced thermally in the aircraft engine combustion process. As a consequence of these studies, various governments instigated research programs to clarify the potential environmental effects of aircraft operations in the stratosphere. In the U.S., concurrent, but independent, studies were conducted by the Department of Transportation's Climatic Impact Assessment Program (CIAP, 1974, 1975 a, b) and by the National Academy of Sciences (NAS, 1975). Several independent assessments were also carried out in Europe (COMESA, 1976; COVOS, 1976). A subsequent study to CIAP, the High Altitude Pollution Program (HAPP) sponsored by the U.S. Department of Transportation, continued studies on potential aircraft effects at a lower research level until 1980.

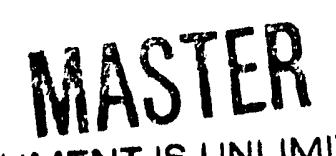


The basic conclusions of these assessment studies were similar, but with some differences in the estimated magnitudes of the environmental effects. Large-scale aircraft operations in the stratosphere were concluded to lead to significant and potentially unacceptable levels of ozone destruction. Most of the ozone reduction was estimated to be caused by emissions of nitrogen oxides with a small effect due to water vapor emissions. However, the small fleet (30 or less) estimated for Concorde-type supersonic transport was determined to have little impact on global ozone or climate.

The primary research tool for investigating the potential effects of aircraft emissions on stratospheric throughout the periods of CIAP and HAPP was the one-dimensional (1-D) chemical-radiative-transport model of the global atmosphere. Such models, including the one at LLNL, determine the vertical distributions of the important trace constituents in the atmosphere, and have the advantage of being computationally efficient while including detailed representations of atmospheric chemical and radiative processes. However, the treatment of atmospheric dynamical processes in these models through an empirically based eddy diffusion representation has well-recognized limitations (WMO, 1985).

Although the two-dimensional (latitude and altitude) chemical-radiative-transport model to be described below is now our primary research tool for stratospheric chemistry studies, we have continued to maintain a baseline of the calculated one-dimensional model effects on ozone for the standard CIAP aircraft scenario (as well as for a standard chlorofluorocarbons, CFCs, emissions scenario, as shown in Figure 1). The results in Figure 1 show the effects of the maturing of stratospheric science from the time of the early CIAP analyses when stratospheric chemistry was comparatively poorly understood. The effects on ozone for this scenario varied considerably throughout the 1970s, even going positive for a two year period while the understanding of hydrogen $\left(\mathrm{HO}_{\mathrm{x}}\right)$ chemistry was being extensively scrutinized in laboratory kinetics studies. By 1988, the calculated ozone reduction by $\mathrm{NO}_{\mathrm{x}}$ emissions at $20 \mathrm{~km}$ (the peak altitude of the original proposed U.S. SST) was about the same as it was at the conclusion of CIAP in 1974. The current model gives essentially the same result as the 1988 version.

A number of countries have shown renewed interest in the development of fast, high flying aircraft for intercontinental passenger flights. Such high speed civil transports (HSCTs) could reduce international travel time by a factor of two or more. The aircraft industry appears to be corifident that such high-speed civil transports can be designed, and that these aircraft will be economically viable as long as they are also environmentally acceptable. As such, it is important to establish the potential for such environmental problems early in the aircraft design.

The first detailed sensitivity analysis in almost a decade of the effects from aircraft emissions on ozone was published by Johnston et al., in 1989 (part of this work also appeared in Kinnison et al., 1988). Both the LLNL one-dimensional and two-dimensional (2-D) models of the global atmosphere were used in this study. The one-dimensional model provides a historical perspective along with having computational advantages for multiple sensitivity calculations, while the twodimensional model provides information on seasonal and latitude effects as well as having a stronger theoretical basis for its representation of atmospheric transport processes. Major findings from this study were:

1. Nitrogen oxides from the exhaust gases of a fleet of HSCTs can reduce stratospheric ozone on a global basis. These calculated ozone reductions depend strongly on the altitude and magnitude of the $\mathrm{NO}_{x}$ injection. Figure 2 (based on the results of Johnston, et al., but not 
Calculated ozone-column change to steady state for two standard assumed perturbations

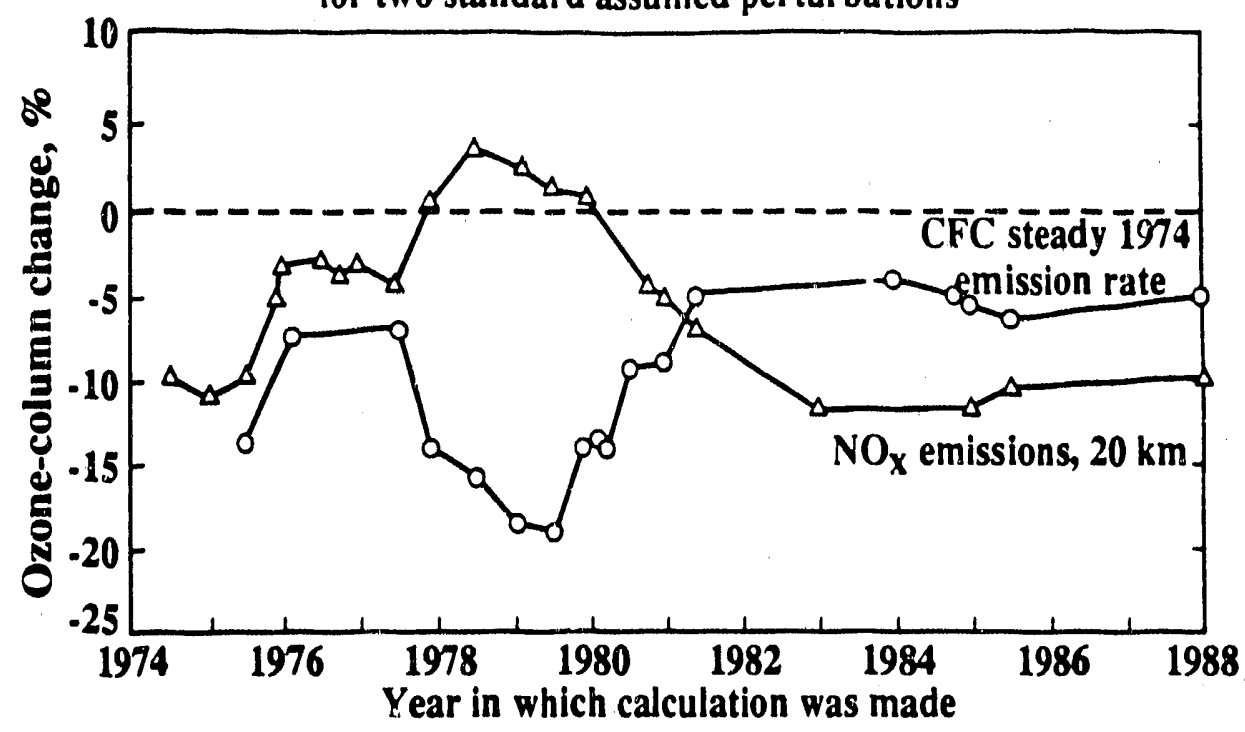

Figure 1. Calculated change in the total ozone column at steady state for two standard assumed perturbations: (a) the standard CIAP scenario for emissions of $\mathrm{NO}_{x}$ at 2000 molecules $\mathrm{cm}^{-3} \mathrm{~s}^{-1}$ over a $1 \mathrm{~km}$ altitude interval centered at $20 \mathrm{~km}$, and (b) continuous emissions of CFC-11 and CFC-12 at 1974 rates. The LLNL one-dimensional model was used in all calculations over this 14-year period; the calculations are based on the version of the model with chemistry and physics treatments that were either recommended or considered current for that particular year.

Percentage change of ozone vertical column stratospheric $\mathrm{Cl}_{\mathrm{x}}=3.1 \mathrm{ppbv}$

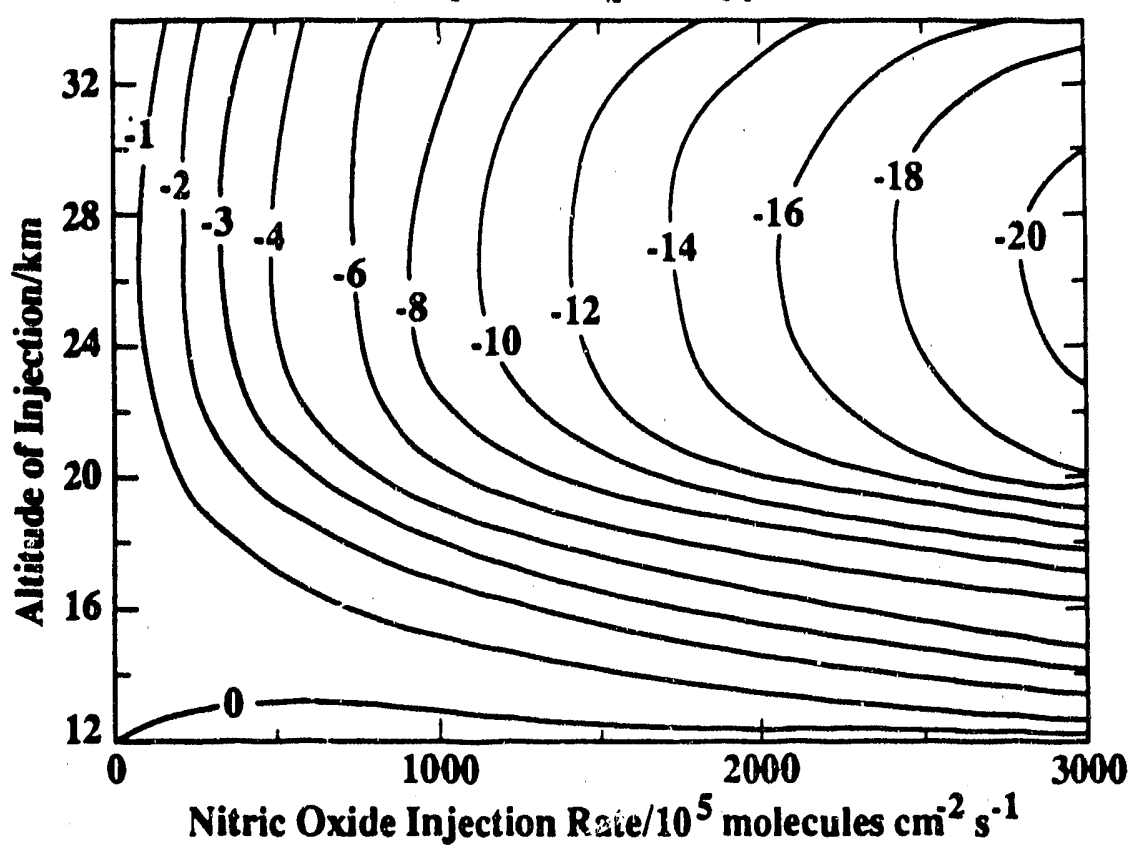

Figure 2. Percentage change in the toial ozone column as calculated with the LLNL onedimensional model as a function of the altitude and magnitude of the $\mathrm{NO}_{\mathbf{x}}$ injection. The emissions are in units of molecules $\mathrm{cm}^{-3} \mathrm{~s}^{-1}$ over a $1 \mathrm{~km}$ band centered at the stated altitude. The percentage change in ozone is relative to a reference atmosphere that contains $3.1 \mathrm{ppbv}$ of stratospheric chlorine $\left(\mathrm{Cl}_{\mathbf{x}}\right)$. 
presented in the paper) shows one-dimensional model results indicating that $\mathrm{NO}_{\mathrm{x}}$ injections below about $13 \mathrm{~km}$ cause an increase in the total ozone column, while injections above $13 \mathrm{~km}$ result in a net destruction of ozone.

2. The altitude at which $\mathrm{NO}_{\mathrm{x}}$ emissions cause the largest reduction in the ozone column is about $25 \mathrm{~km}$ in the one-dimensional model and about $28 \mathrm{~km}$ in the two-dimensional model.

3. For a given altitude and magnitude of $\mathrm{NO}_{x}$ emissions, the two-dimensional model indicates that the reduction of global ozone depends on the latitude of the injections, with the maximum ozone reduction for tropical injection. For a given injection, the largest ozone column reductions occur in the polar regions.

4. For extremely large stratospheric chlorine $\left(\mathrm{Cl}_{\mathbf{X}}\right)$ mixing ratios ( $\sim 8$ ppbv compared to about 3 ppbv in the current atmosphere), $\mathrm{NO}_{x}$ emissions can increase the ozone column, partially counteracting the ozone reduction caused by the chlorine. This effect is only found in a highly $\mathrm{Cl}_{\mathbf{x}}$ perturbed stratosphere where ozone is already greatly depleted.

5. Water vapor (without $\mathrm{NO}_{\mathbf{x}}$ ) emissions cause a small ozone reduction; water vapor and $\mathrm{NO}_{\mathbf{x}}$ together give an ozone reduction less than that calculated for $\mathrm{NO}_{\mathrm{x}}$ emissions alone by a factor between 0.85 and 0.97 , depending on the altitude and magnitude of the emissions.

6. Calculated global reductions of ozone due to $\mathrm{NO}_{\mathrm{x}}$ emissions are smaller in the twodimensional model than in the one-dimensional model, by factors that range from 0.66 to 0.86 for injection altitudes between 20 to $34 \mathrm{~km}$. [More recent calculations show a sensitivity in the two-dimensional model to uncertainties in the treatment of eddy transport processes (Kinnison, 1989).]

7. On the basis of an uncertain estimate of fuel consumption by future stratospheric aircraft, two-dimensional model calculations for a fleet of 500 aircraft operating at $22 \mathrm{~km}$ with $\mathrm{NO}_{\mathrm{x}}$ emission properties of 1988 subsonic commercial aircraft engines give a global ozone reduction of $19 \%$ (assuming emissions occur between $37^{\circ}-49^{\circ} \mathrm{N}$ ). The effect of reducing the emission index for the amount of $\mathrm{NO}_{\mathbf{x}}$ produced per $\mathrm{kg}$ of fuel burned is shown in Table 1 .

The purpose of this study is to build on the previous analyses of potential aircraft emission effects on ozone in order to better define the sensitivity of ozone to such emissions. A preliminary analysis is made of the sensitivity of the ozone distribution to the current fleet of commercial aircraft. The future emissions scenarios evaluated in this study attempt to more accurately account for the spread in emissions with latitude and altitude for an assumed fleet of HSCTs. The tirne it would take for the atmosphere to recover from the effects on ozone after emissions are ceased is also examined. In addition to emissions of $\mathrm{NO}_{\mathbf{x}}$, the effects of potential emissions of carbon monoxide and water vapor are also evaluated. These analyses are all based on results from the LLNL two-dimensional chemical-radiative-transport model of the troposphere and stratosphere. 
Table 1. Calculated change in global-averaged total ozone from the LLNL two-dimensional model assuming an annual fuel consumption of $7.7 \times 10^{10} \mathrm{~kg}$, with all emissions between $37^{\circ}-$ $49^{\circ} \mathrm{N}$ in a $3 \mathrm{~km}$ altitude range centered about $22.5 \mathrm{~km}$ altitude (relative to an atmosphere with no aircraft emissions), based on Johnston, et al. (1989).

\begin{tabular}{lcccc}
\hline & $\begin{array}{c}\text { Emission Index } \\
\text { g of NO }\end{array}$ & \multicolumn{2}{c}{ Injection Rate } & \\
\cline { 3 - 4 } Emission Scenario & $\mathrm{Kg}^{-1}$ Fuel & $\mathrm{Mr} \mathrm{of} \mathrm{NO}_{2}$ & $\begin{array}{c}\text { Molecules/ } \\
1 \mathrm{Yr}^{-1}\end{array}$ & $\begin{array}{c}\text { Change in } \\
\text { Total Ozone }\end{array}$ \\
\hline Current Subsonic Rate & $40^{*}$ & 4.8 & 4000 & $-19.0 \%$ \\
Standard CIAP Rate & 15 & 1.8 & 1500 & $-8.6 \%$ \\
Future Goal & 5 & 0.6 & 500 & $-2.8 \%$ \\
\hline
\end{tabular}

* This emission index assumes current commercial subsonic aircraft technology being used in the stratosphere. The actual emission index for current aircraft at their flight altitudes in the upper troposphere are a factor of 2-3 smaller than this.

\section{THE LLNL TWO-DIMENSIONAL MODEL}

The two-dimensional model of the global atmosphere provides a zonally-averaged representation of the chemical and physical processes determining the composition and distributions of trace constituents in the troposphere and stratosphere. The concentrations of 35 chemically active trace constituents, based on more than 100 chemical and photochemical reactions, are calculated as a function of altitude, latitude, and season within the model. Essentially the model determines the atmospheric distribution of ozone and other important constituents based on the interactions of chemical, radiative, and dynamical transport processes thought to be operating in the atmosphere. For the version of the model used here, the diabatically-driven circulation is determined for the current (background) atmosphere using observed temperatures along with model-derived radiative transfer calculations of the net solar and longwave heating, determined in an internally consistent way with the derived species distributions. For the perturbed atmosphere, a perturbation form of the thermodynamic equation is solved for the changes in stratospheric temperatures resulting from the changes in ozone and other radiatively important trace constituents (note that the diabatic circulation is assumed to be unchanged from the current atmosphere for these calculations). More detailed descriptions of the two-dimensional model can be found in Wuebbles and Kinnison (1989), Johnston, et al. (1989), and Kinnison (1989).

\section{CURRENT AIRCRAFT EMISSIONS}

Earlier calculations with the one-dimensional model (Wuebbles, 1983) suggested that emissions from the existing, primarily subsonic, fleet of commercial aircraft could affect upper tropospheric ozone, resulting in increased concentrations of ozone in the region just below the tropopause. However, the one-dimensional model is of limited use in evaluating changes in tropospheric chemistry. Even the two-dimensional model is somewhat limited in treating tropospheric chemistry, particularly in the lower troposphere, because of the significant impact of emissions from highly reactive species primarily produced over land; only a three-dimensional model can be used to fully evaluate the effects on the global atmosphere from such emissions. Nonetheless, the two-dimensional model provides a useful test of how sensitive the troposphere may be to aircraft emissions primarily occuring in the upper troposphere. 
One of the difficulties in evaluating the effects of existing aircraft emissions is that there isn't an available evaluation of the trends in such emissions over the last several decades. The most complete estimate of current emissions comes from the analysis of commercial aircraft flights for 1987 in a recent analysis by Boeing Corporation (Boeing, 1989). Slightly more than 29,000 citypairs were accounted for in their analysis, along with the appropriate aircraft types and flight frequencies. The analysis determined emissions of nitrogen oxides, carbon monoxide, and hydrocarbons at 26,000 feet (about $8 \mathrm{~km}$ ) and 37,000 feet (about $11 \mathrm{~km}$ ). Figure 3a shows a coritour plot of the $\mathrm{NO}_{\mathbf{x}}$ emissions from the Boeing analysis. Bauer (1978) published an estimate of the 1975 subsonic aircraft emissions that had about a factor of 3.4 less $\mathrm{NO}_{x}$ emitted than the assumed emissions for 1987. If this earlier emissions estimate is correct, there was a sizable increase in aircraft emissions during the 12 years between 1975 and 1987.

The two-dimensional model is used to evaluate the effects on ozone concentrations resulting from the 1987 fleet emissions compared to an ambient atmosphere with no aircraft emissions. Emissions of nitrogen oxides, carbon monoxide, and hydrocarbons were included in the calculation based on the Boeing analysis; the hydrocarbon emissions were assumed to have the same reactivity as methane, as there was no attempt in this preliminary study to represent the complexity of non-methane hydrocarbon chemistry in this version of the model.

The calculated response of the ozone distribution to the emissions for the 1987 fleet are shown in Figures $3 \mathrm{~b}$ and $3 \mathrm{c}$. The largest increase in ozone occurs near $9 \mathrm{~km}$ at midlatitudes in the Northern Hemisphere, corresponding to the altitude and latitude of the maximum emissions. Approximately a 5\% maximum increase in ozone is determined in July, primarily due to the effect of the $\mathrm{NO}_{x}$ (see Table 2) emissions to produce ozone in the troposphere through smogformation reactions (e.g., see WMO, 1985). The global-averaged change in total ozone is $0.45 \%$, with the maximum change of $0.6 \%$ occurring at high latitudes in the Northern Hemisphere.

Table 2. Sensitivity analyses to determine the relative importance of $\mathrm{NO}_{\mathrm{x}}, \mathrm{CO}$, and hydrocarbon (represented as $\mathrm{CH}_{4}$ emissions) on the calculated change in total ozone for the current aircraft emissions scenario.

\begin{tabular}{lccc}
\hline & \multicolumn{3}{c}{ Change in total ozone (\%) } \\
\cline { 2 - 4 } & Global & $\begin{array}{c}\text { Northern } \\
\text { Hemisphere }\end{array}$ & $\begin{array}{c}\text { Southern } \\
\text { Hemisphere }\end{array}$ \\
\hline $\mathrm{NO}_{\mathrm{x}}+\mathrm{CO}+\mathrm{CH}_{4}$ & 0.45 & 0.53 & 0.37 \\
$\mathrm{NO} x$ only & 0.44 & 0.52 & 0.36 \\
$\mathrm{CO}$ only & 0.018 & -0.0058 & 0.043 \\
$\mathrm{CH}_{4}$ only & 0.024 & 0.0031 & 0.045 \\
\hline
\end{tabular}

A trend analysis of ozonesonde measurements from nine stations at latitudes from $32^{\circ} \mathrm{N}$ to $75^{\circ} \mathrm{N}$ has been recently made for the years from 1965 through 1986 (WMO, 1989). Significant increases in ozone concentrations were determined throughout the troposphere, with the largest increase (+0.83\% per year for the period from 1970 to 1986) occurring in the bottom $3 \mathrm{~km}$ of the atmosphere. A secondary peak in the ozone increase (+ $0.38 \%$ per year or $6 \%$ over the 16 year period of the trend estimate) was found at altitudes between 8 and $10 \mathrm{~km}$, just below the tropopause. Although it is premature to attribute causality, it is interesting that the secondary peak occurs at the same altitude and magnitude as the calculated effect from subsonic aircraft emissions. Aircraft emissions may explain a substantial fraction of the observed ozone increase in the upper troposphere. However, one should be extremely cautious in interpreting the global implications of such a limited data set. 


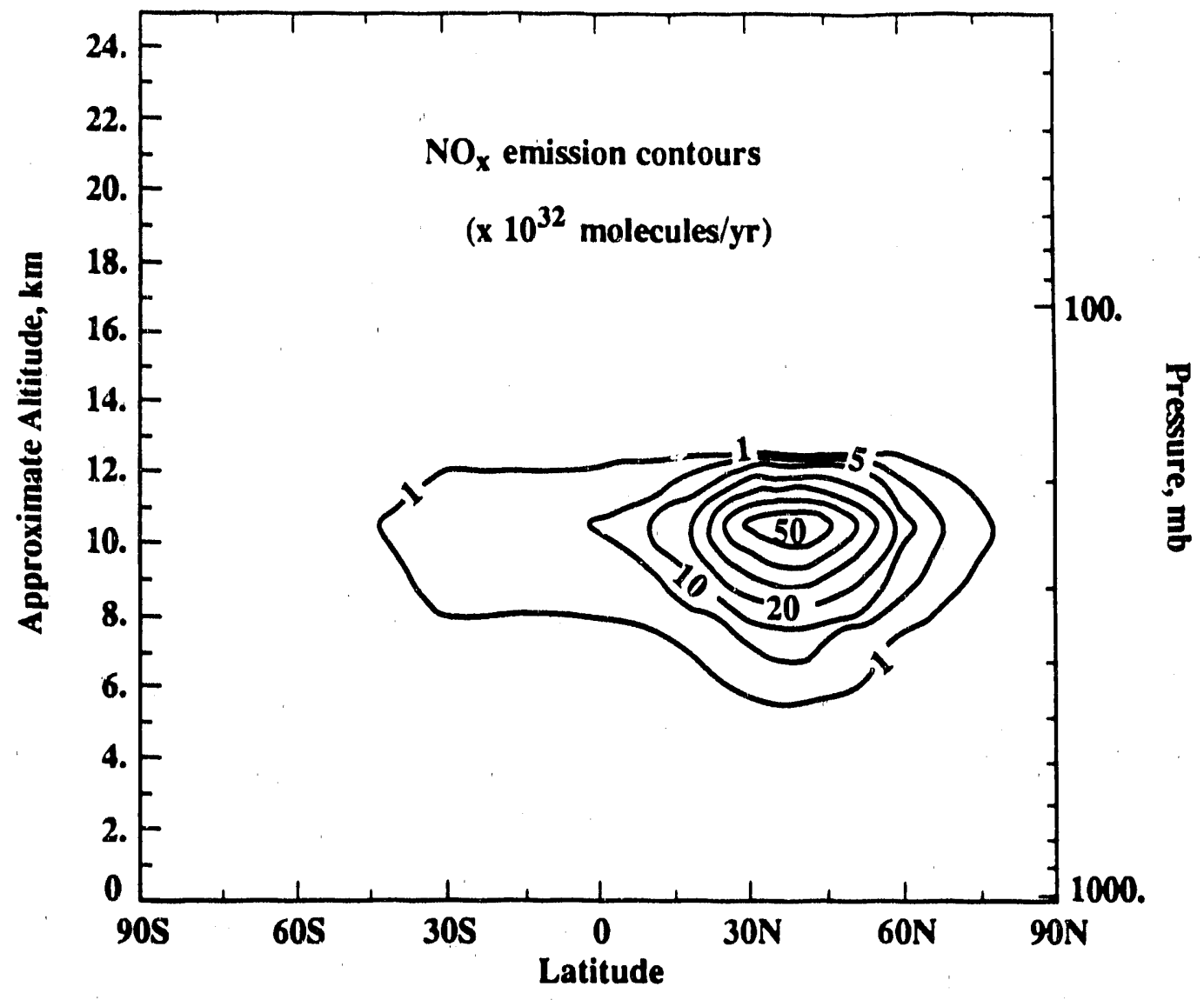

Figure 3(a)

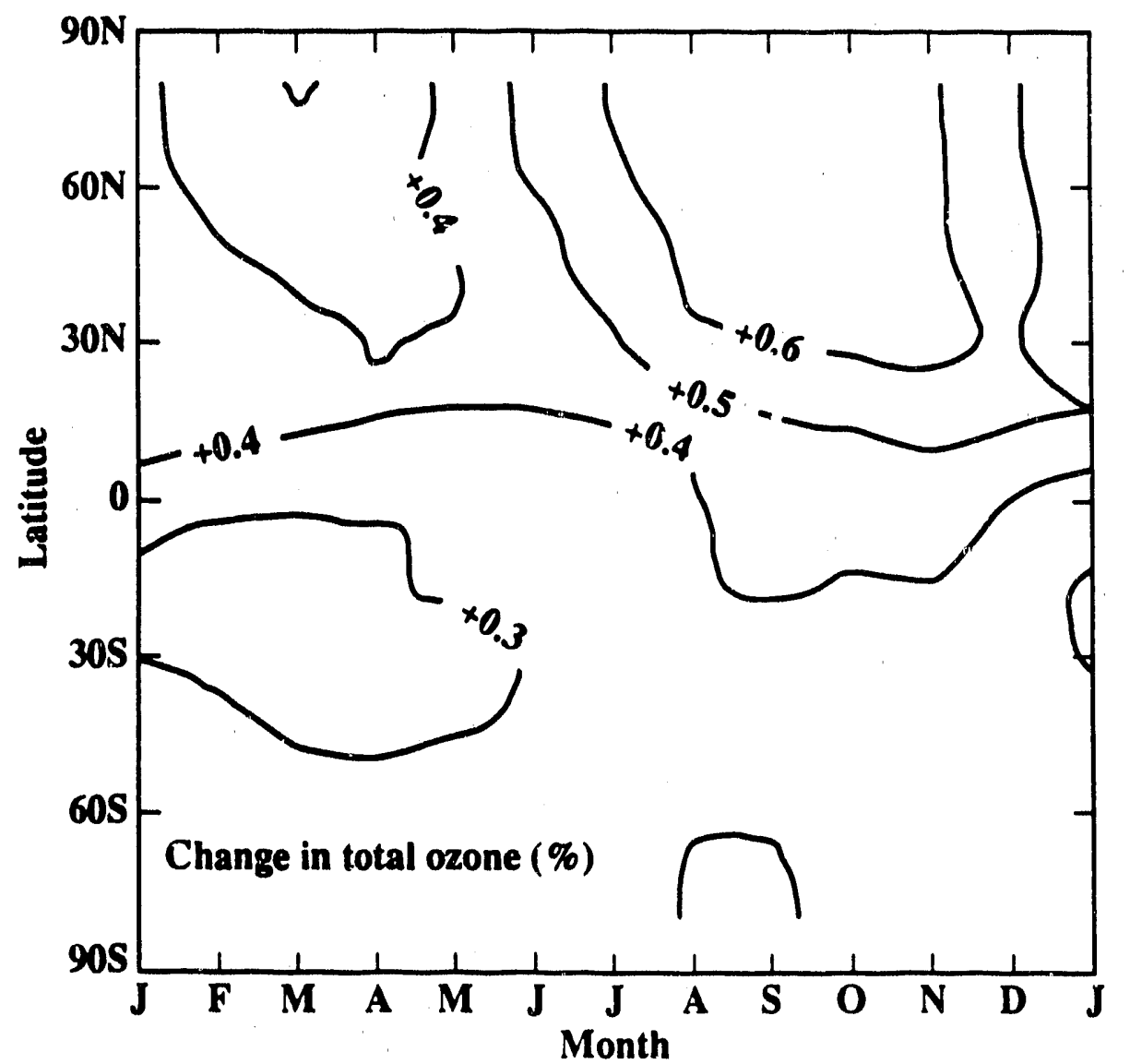

Figure 3(b) 


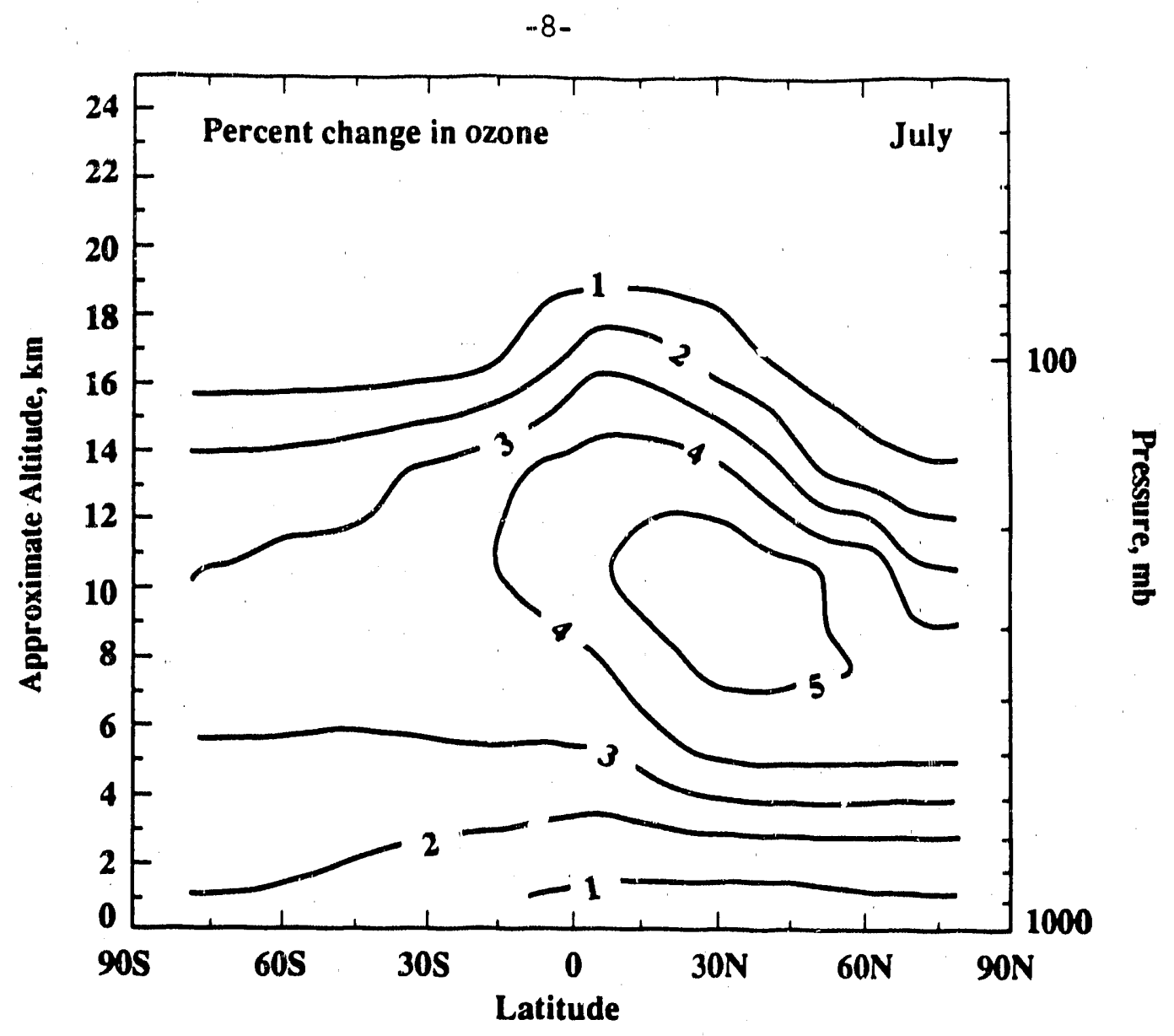

Figure 3(c)

Figure 3. (a) Contour of the $\mathrm{NO}_{\mathrm{x}}$ emis $;$ ions as a function of altitude and latitude determined by Boeing (1989) in their evaluation of the commercial aircraft emissions for the year 1987; (b) Calculated percentage change in total ozone at steady-state plotted as a function of latitude and time of the year as determined in the LLNL two-dimensional model for the 1987 subsonic aircraft fleet compared to an atmosphere without aircraft emissions; (c) Calculated percentage change in ozone at steady-state plotted as a function of altitude and latitude as determined for the 1987 subsonic aircraft fleet dering the month of July .

\section{A MATRIX OF FUTURE EMISSIONS}

The amount of nitrogen oxides and other gases emitted into the atmosphere by a fleet of commercial aircraft depend on a number of factors, including the fleet size, engine fuel efficiency, the aircraft range, the cruise altitude, flight operational procedures, and the emission index for amount of $\mathrm{NO}_{x}$ produced per $\mathrm{kg}$ of fuel burned. Possible designs for HSCT aircraft and their engines are still at an early stage; therefore, most of the factors determining emissions of an actual fleet are still unknown. Examining a wide range of possible flight altitud.: and levels of emissions for the effects on ozone will help establish the design criteria needed to prevent an unacceptable environmental problem.

In this study, we have evaluated a total of twelve HSCT fleet scenarios assuming three different cruise altitudes and varying levels of $\mathrm{NO}_{x}$ emissions. These hypothetical scenarios were dev- 
eloped by the HSCT group at McDonnell Douglas Corporation in a cooperative effort to establish a matrix of scenarios witk realistic assumptions for flight altitudes versus magnitude of emissions. In no manner are these scenarios based on actual aircraft designs; they are intended to cover a broad range of aircraft altitudes and emissions. These scenarios attempt to consider how the emissions should vary with latitude and altitude appropriate to a worldwide fleet of HSCTs. No subsonic aircraft emissions were considered in these scenarios. Three different aircraft, flying at different mean cruise altitudes, were assumed in the scenarios; the mean cruise altitudes were $15.8,18.3,22.9 \mathrm{~km}$, although changes in flight altitudes throughout the flight patterns assumed in the scenarios are accounted for. Ten different city-pairs were chosen by McDonnell Douglas to represent the appropriate regions for intercontinental flights; these flight patterns combined with the assumed aircraft type provide the criteria for the altitude and latitude of the aircraft emissions. A wide range of $\mathrm{NO}_{\mathbf{x}}$ emissions were assumed, based on uncertainties in fleet size, fuel burned, and $\mathrm{NO}_{\mathrm{x}}$ emission index. All scenarios assume that a kerosene based fuel will be used in the HSCT in contrast to a more exotic fuel such as liquid methane or hydrogen.

Table 3 indicates the mean cruise altitude and the total global $\mathrm{NO}_{\mathrm{x}}$ emissions for the 12 scenarios. Figure 4 shows the $\mathrm{NO}_{x}$ emissions assumed in scenario $\mathrm{cl}$, corresponding to a mean flight altitude of $22.3 \mathrm{~km}$, a total $\mathrm{NO}_{x}$ emission of $0.28 \mathrm{Mt}$ per year (as $\mathrm{NO}_{2}$ ) or $3.64 \times 10^{33}$ molecules per year. The $\mathrm{NO}_{\mathrm{x}}$ emissions for scenarios with the other mean cruise altitudes look very similar to Figure 4, except maximum emissions occur at lower altitudes.

For each of the 12 scenarios, Table 3 shows the calculated change in toral ozone column for each hemisphere, along with the global averaged change in ozone. These calculations are based on a background stratospheric chlorine level of $2.9 \mathrm{ppbv}$, corresponding to current concentrations.

Table 3. Annually-averaged change in ozone for the twelve emissions scenarios evaluated with the LLNL two-dimensiorial model.

\begin{tabular}{|c|c|c|c|c|c|}
\hline \multirow[b]{2}{*}{ Scenarios } & \multirow{2}{*}{$\begin{array}{c}\text { Mean } \\
\text { Cruise } \\
\text { Altitude } \\
(\mathrm{km})\end{array}$} & \multirow{2}{*}{$\begin{array}{c}\text { Total } \\
\mathrm{NO}_{\mathrm{x}} \text { Emissions } \\
\left(\times 10^{33} \text { Molecules } / \mathrm{Yr}\right)\end{array}$} & \multicolumn{3}{|c|}{$\Delta O_{3} / \%$} \\
\hline & & & N.H. & S.H. & Global \\
\hline $\mathrm{a} 0$ & 15.8 & 0.67 & -0.20 & -0.18 & -0.19 \\
\hline al & 15.8 & 4.18 & -0.43 & -0.33 & -0.38 \\
\hline $\mathrm{a} 2$ & 15.8 & 17.89 & -1.53 & -1.00 & -1.27 \\
\hline a3 & 15.8 & 58.31 & -5.50 & -3.35 & -4.44 \\
\hline b0 & 18.3 & 0.63 & -0.25 & -0.22 & -0.23 \\
\hline b1 & 18.3 & 3.29 & -0.71 & -0.52 & -0.61 \\
\hline b2 & 18.3 & 16.58 & -3.47 & -2.24 & -2.86 \\
\hline b3 & 18.3 & 54.02 & -12.18 & -7.63 & -9.93 \\
\hline $\mathrm{cO}$ & 22.9 & 0.58 & -0.28 & -0.23 & -0.25 \\
\hline cl & 22.9 & 3.64 & -1.00 & -0.64 & -0.82 \\
\hline$c 2$ & 22.9 & 15.32 & -4.22 & -2.42 & -3.33 \\
\hline c3 & 22.9 & 49.98 & -14.45 & -8.17 & -11.34 \\
\hline
\end{tabular}

Although more realistic scenarios for the assumed emissions are used here than in the prior Johnston, et al. sensitivity analyses, the main conclusion is similar: the largest effects on total column ozone occur with the largest $\mathrm{NO}_{\mathrm{x}}$ emissions and the highest assumed flight altitude. The Northern Hemisphere has the largest decreases in total ozone. Figure 5 shows the change in 
globally and annually averaged total ozone as a function of the altitude and magnitude of the emissions. This figure indicates that, for these scenarios, the assumed HSCT fleet would need to keep $\mathrm{NO}_{\mathrm{x}}$ emissions below 0.5-1 $\times 10^{34}$ molecules per year, depending on the aircraft flight altitude, in order to affect globally-averaged total ozone by one percent or less. Using a one percent criteria in this discussion is entirely arbitrary, since humanity has yet to determine what is an acceptable level of ozone destruction from such emissions. Figure 6 shows that the change in globally and annually averaged total ozone varies almost linearly with the magnitude of the $\mathrm{NO}_{\mathrm{x}}$ emissions, assuming that the altitude and latitude variations in the emissions remain unchanged.

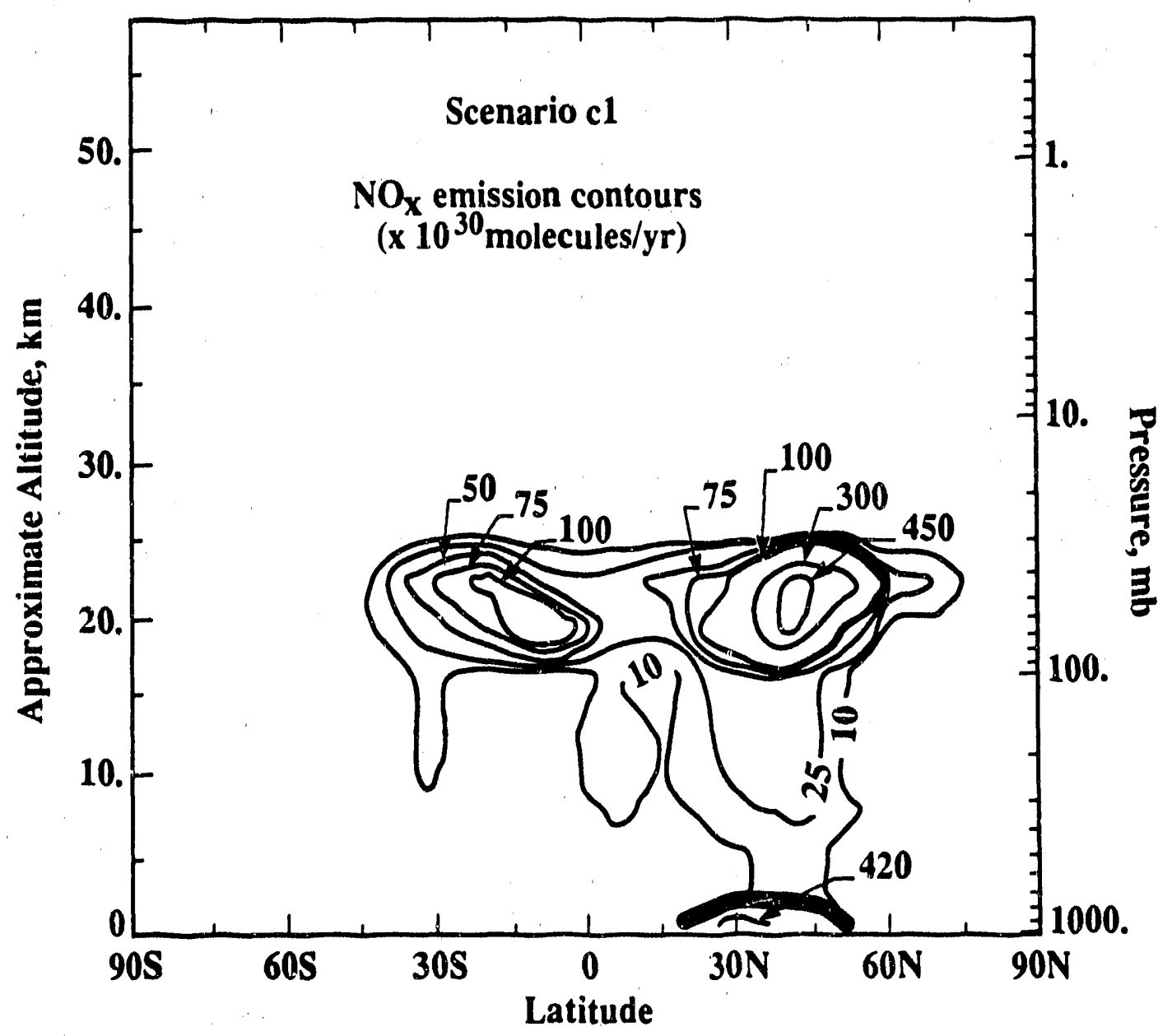

Figure 4. Emissions of $\mathrm{NO}_{\mathbf{x}}$ as a function of altitude and latitude assumed in scenario $\mathrm{cl}$, corresponding to an aircraft flying at a mean cruise altitude of $22.3 \mathrm{~km}$ and a total emissions of $3.64 \times 10^{33}$ molecules of $\mathrm{NO}_{x}$ per year. 


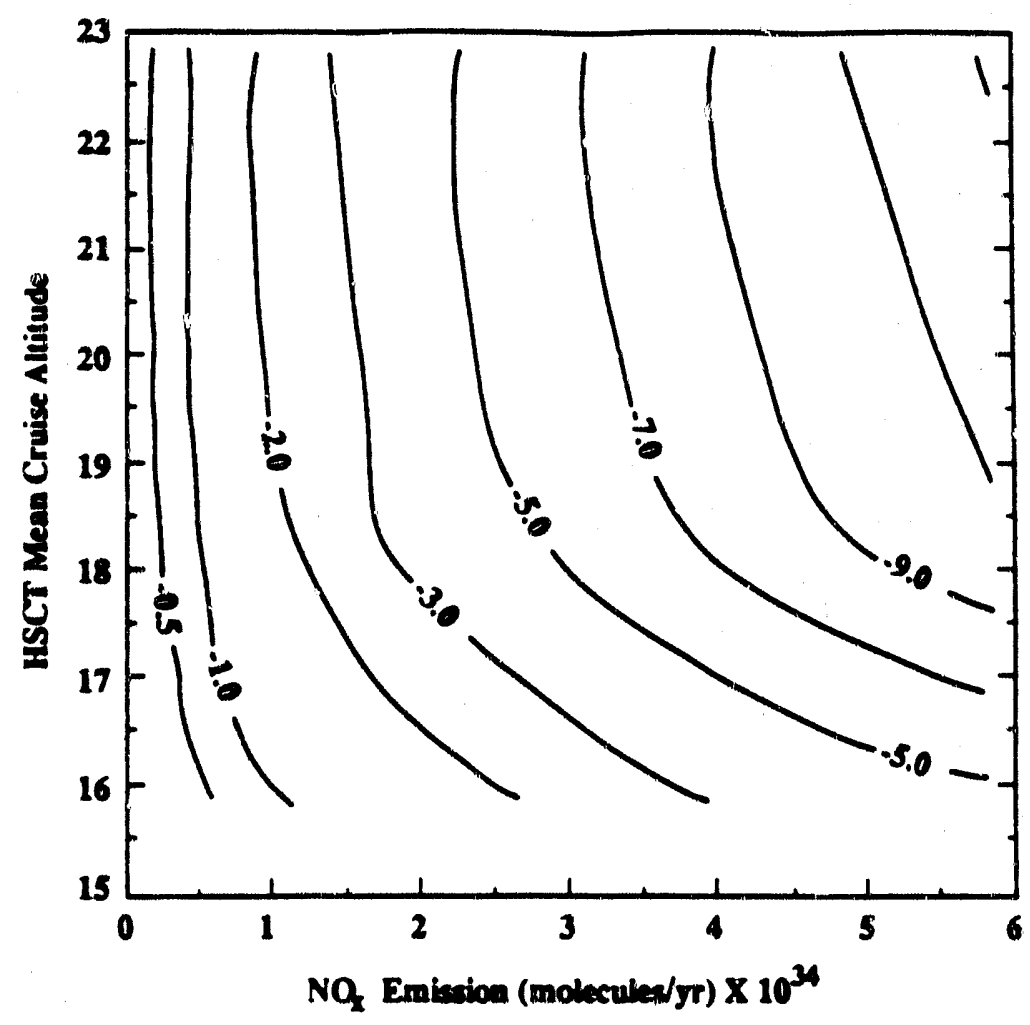

Figure 5. Change in globally and annually averaged total ozone at steady-state plotted as a function of mean cruise altitude and amount of $\mathrm{NO}_{x}$ emissions assumed in the twelve scenario matrix.

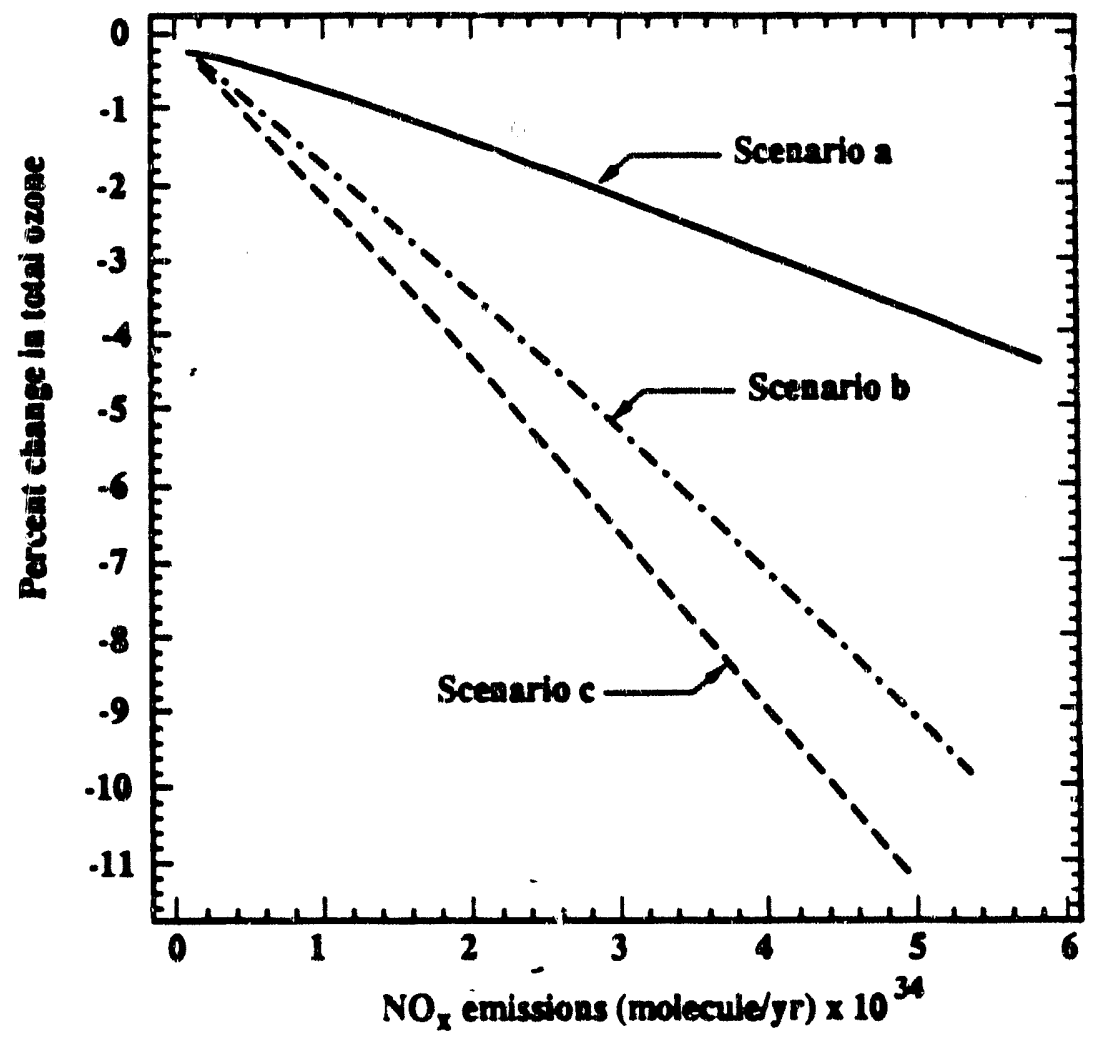

Figure 6. Change in globally and annually averaged total ozone as a function of $\mathrm{NO}_{\mathrm{x}}$ emissions for aircraft scenarios with mean cruise altitudes of 15.9, 18.3, and 22.3. 
Figure $7 \mathrm{a}$ gives the change in total ozone versus time of year for scenario $\mathrm{cl}$, while Figure $7 \mathrm{~b}$ shows the change in ozone versus altitude and latitude for the same scenario. The maximum change in total ozone occurs at high Northern Hemisphere latitudes and peaks in late summer and into fall. The minimum decrease in total ozone occurs in the tropics. Figure $7 b$ shows that the maximuin ozone destruction for this scenario occurs near $20 \mathrm{~km}$ altitude in Northern Hemisphere polar region.

Part of the intention in undertaking this analysis is to develop the appropriate criteria needed by the aircraft industry to ensire that the HSCT developed is not environmentally harmful. The U.S. aircraft ccinpanies are well-aware of the concerns about ozone and, through NASA's HSCT research program, are aware of our research. Because this matrix of scenarios extends over such a wide range of emissions we want to be careful that the results for these scenarios are not overinterpreted. We do not want to imply that the large emission cases in any way correspond to any fleet under actual consideration. In fact, our results suggest that the larger emission cases will need to be avoided in considering fleet designs.

\section{OZONE RECOVERY TIME}

Of interest to policymakers is the question of how long it takes for the ozone concentrations to recover if the emissions are greatly reduced. For scenarios 22, b2, and c2, Figure 8 shows that it takes about nine years after emissions begin for the maximum change in total ozone to be reached, and about an additional decade for the globally-averaged ozone column to recover to unperturbed conditions after emissions cease. The altitude of the emissions appears to make littie difference in the recovery time.

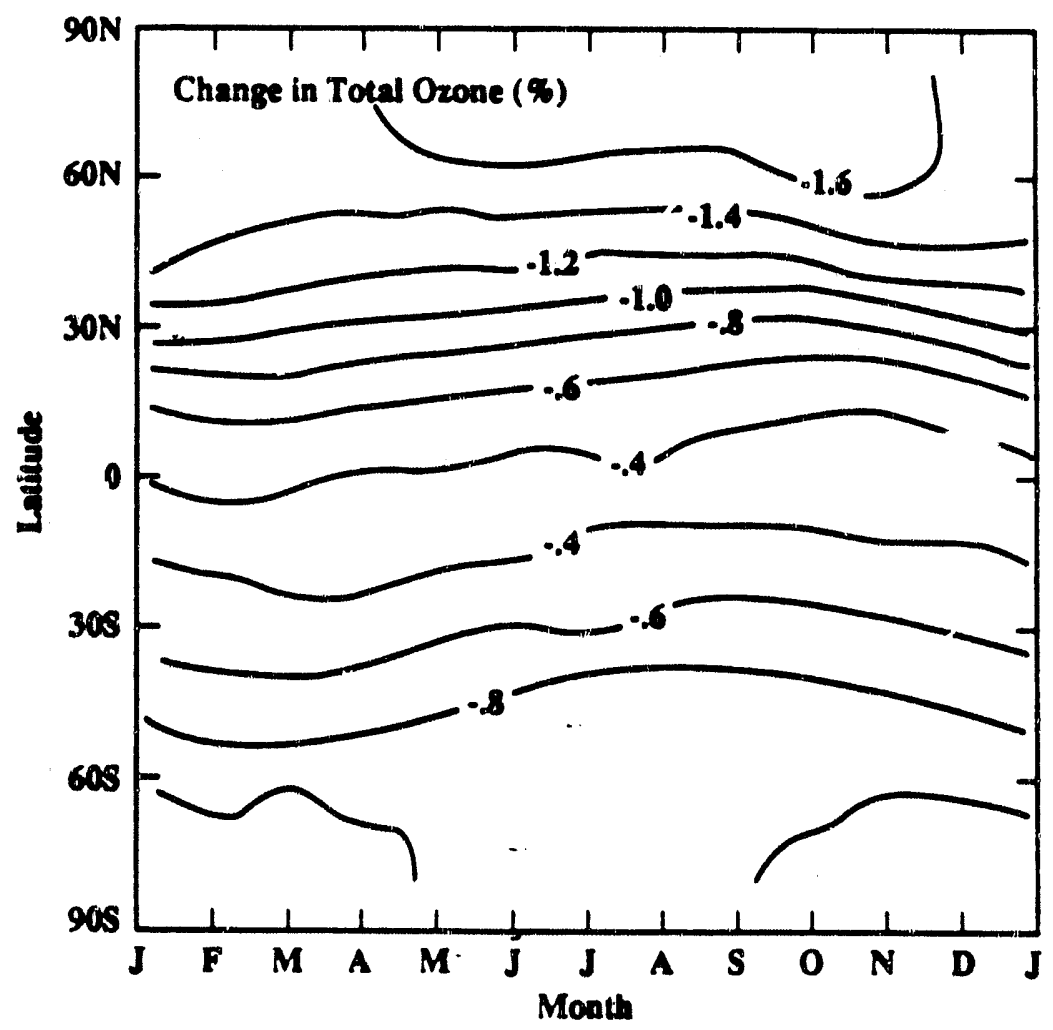

Figure 7(a) 


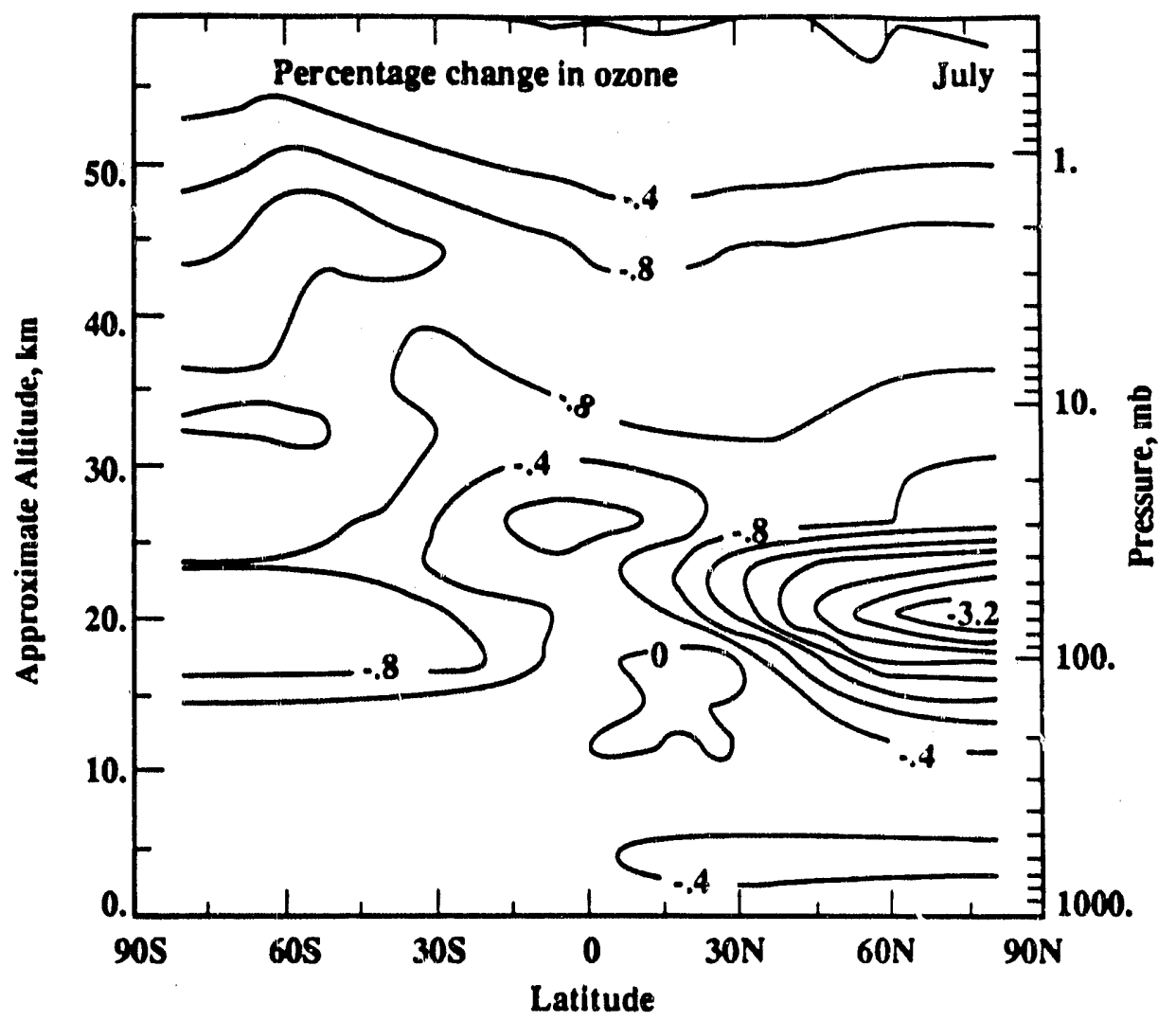

Figure 7(b)

Figure 7. (a) Calculated percentage change in total ozone at steady-state plotted as a function of latitude and time of the year as determined for scenario $\mathrm{cl}$; (b) Calculated percentage change in ozone at steady-state plotted as a function of altitude and latitude as determined for scenario $\mathrm{cl}$ during the month of July.

\section{FURTHER SENSITIVITY STUDIES}

This evaluation of the future HSCT fleet scenarios has, until this section, considered the effects on ozone resulting from $\mathrm{NO}_{x}$ emissions only. Several sensitivity calculations are evaluated here based on assumed emissions of water vapor and carbon monoxide. These estimated emissions are based on current engine technology. An additional sensitivity calculation will consider the effect on the calculated ozone changes of a future atmosphere with higher background stratospheric chlorine along with increased concentrations of $\mathrm{CO}_{2}, \mathrm{CH}_{4}$, and $\mathrm{N}_{2} \mathrm{O}$.

The stratospheric water vapor emissions due to aircraft emissions for hydrocarbon fuel combustion are much larger than the $\mathrm{NO}_{\mathrm{x}}$ emissions. For scenario $\mathrm{cl}$, this corresponds to about a factor of 370 larger number of molecules of water emitted into the stratosphere than $\mathrm{NO}_{\mathrm{x}}$ emitted. The effect of the water vapor emissions by itself is small, but it has a larger impact when included in combination with the $\mathrm{NO}_{x}$ emissions. The effect on ozone with the coupled $\mathrm{NO}_{x}$ and $\mathrm{H}_{2} \mathrm{O}$ emissions case is a factor of 0.9 less than the $\mathrm{NO}_{x}$ emissions only case. This effect is due the interactions between $\mathrm{NO}_{x}$ and $\mathrm{HO}_{x}$ chemistry.

The effects of carbon monoxide emissions were also evaluated. For scenario $\mathrm{cl}$, the total $\mathrm{CO}$ emissions are $6.24 \times 10^{33}$ inolecules per year, but over half of these emissions occur in the 
bottom $1.5 \mathrm{~km}$ of the atmosphere. We found that the CO emissions had a negligible effect on global ozone.

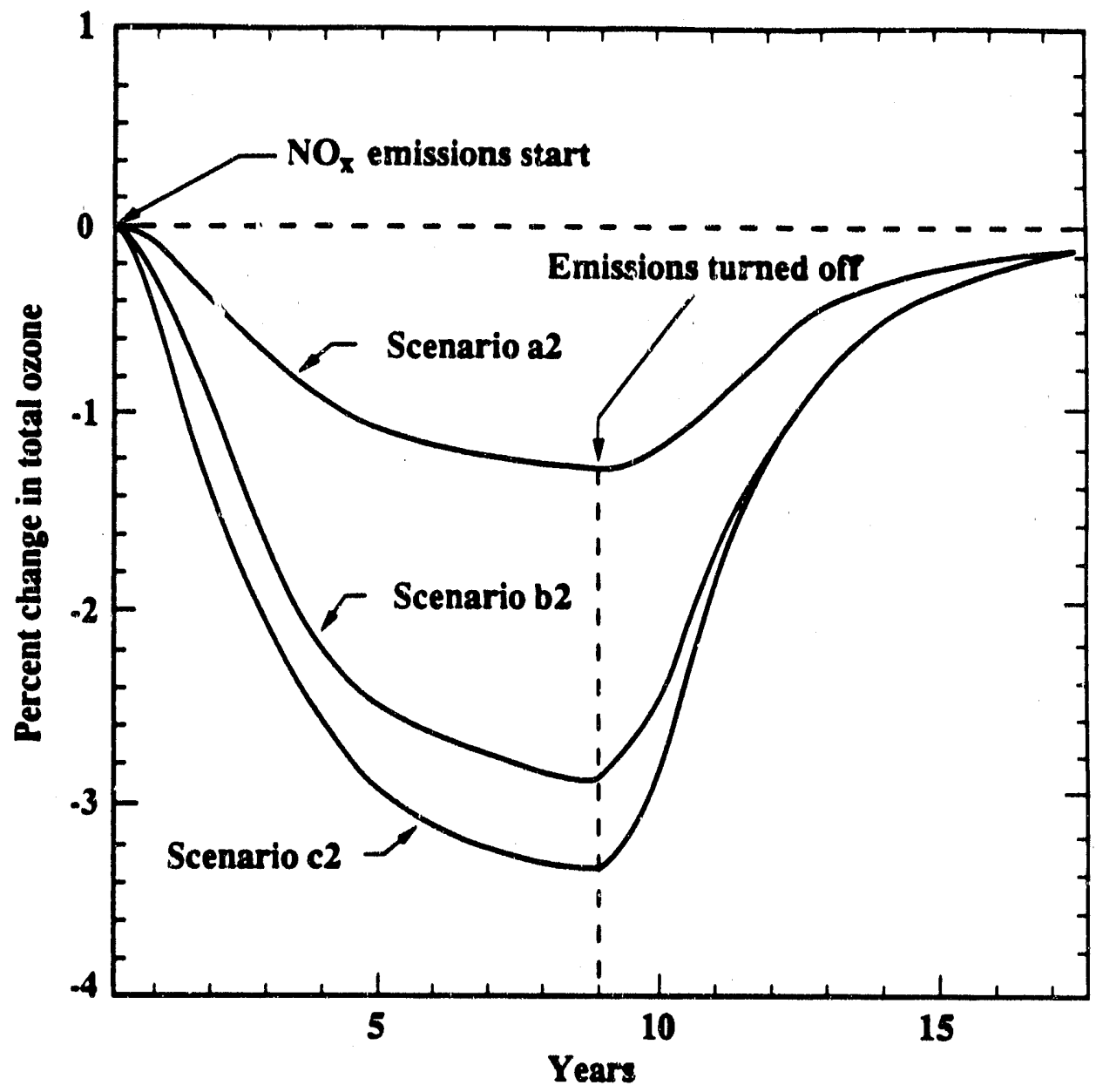

Figure 8. Change in globally and annually averaged total ozone as a function of time after initiating the $\mathrm{NO}_{x}$ emissions for scenarios $22, \mathrm{b2}$, and $\mathrm{c2}$, followed by cessation of all emissions once steady-state has been reached.

As a test of the sensitivity of the aircraft scenario effects to the background atmosphere, we evaluated the effect of the $\mathrm{NO}_{\mathrm{x}}$ emissions in scenario $\mathrm{cl}$ for an atmosphere containing $5.2 \mathrm{ppbv}$ of stratospheric reactive chlorine, $395 \mathrm{ppmv}$ of carbon dioxide, $2.25 \mathrm{ppmv}$ of methane, and 0.334 ppmv of nitrous oxide. This corresponds to the atmosphere in 2020 if one assumes constant emissions of CFCs at 1986 levels, and continuing trends at current rates for $\mathrm{CO}_{2}, \mathrm{CH}_{4}$ and $\mathrm{N}_{2} \mathrm{O}$. In actuality, this level of chlorine will likely not be reached in the next few decades as a result of international efforts to reduce CFC production. However, this chlorine level is useful in evaluating the sensitivity of aircraft emissions to background chlorine levels. There appears to be a large sensitivity to the background atmosphere; the calculation of scenario $\mathrm{cl}$ with the 2020 background atmosphere determines a global total czoni decrease of $-0.58 \%$ as compared to the ozone decrease of $0.82 \%$ calculated using the current atmosphere as the background. The chemical interactions of $\mathrm{NO}_{\mathrm{x}}$ with stratospheric chlorin : are likely responsible for the sensitivity, but the role of the increased background $\mathrm{CO}_{2}, \mathrm{~N}_{2} \mathrm{O}$, and $\mathrm{CH}_{4}$ require further evaluation. 
This study has used the LLNL two-dimensional model of the global atmosphere in an evaluation of the effects on global ozone concentrations from current subsonic aircraft emissions and from the emissions of possible future high speed civil transports. We have attempted to include more realistic representations of emissions as a function of altitude and latitude in these scenarios than were included in previous sensitivity analyses. Major findings from this study are:

1. Current aircraft emissions may be having an impact on upper tropospheric ozone, leading to increasing concentrations of ozone in the upper troposphere. However, the analysis here was very preliminary. The potential significance of the effects on ozone warrant much further study.

2. A matrix of HSCT scenarios evaluated over a wide range of mean flight altitudes and magnitudes of $\mathrm{NO}_{\mathbf{x}}$ emissions confirmed previous analyses showing that ozone destruction becomes larger as the emissions of $\mathrm{NO}_{\mathrm{x}}$ increase and as the altitude of injection increases.

3. Model calculations indicate that a major reduction in emissions would allow the stratosphere to recover to unperturbed conditions in about a decade.

4. Sensitivity studies indicate that water vapor emissions have a moderate effect on the change in total ozone, while carbon monoxide emissions had a negligible effect. Water vapor emissions should be considered in all future evaluations of HSCT fleets.

5. The calculated change in ozone for the HSCT scenarios was very sensitive to the background atmosphere, particularly to the levels of stratospheric chlorine and concentrations of carbon dioxide, methane, and nitrous oxide. This requires further evaluation, but suggests that assessment analyses of future HSCT fleets should carefully consider the appropriate background atmosphere for the time period in which the aircraft will fly. These analyses should also consider projections of subsonic emissions.

\section{ACKNOWLEDGMENTS}

Work at Lawrence Livermore National Laboratory was performed under the auspices of the U.S. Department of Energy under Contract W-7405-ENG-48 and was supported in part by NASA's Upper Atmospheric Research Program.

\section{REFERENCES}

Bauer, E., 1978: A catalog of perturbing influences on stratospheric ozone, 1955-1975, U.S. Department of Transportation report no. FAA-EQ-78-20.

Boeing Commercial Airplanes, 1989: High-speed civil transport study, National Aeronautics and Space Administration Contractor Report 4233.

Climatic Impact Assessment Program, 1974: Report of findings: The effects of stratospheric pollution by aircraft, edited by A. J. Grobecker, S. C. Coroniti, and R. H. Cannon, Jr., U.S. Department of Transportation report DOT-TST-75-50, Washington, D.C. 
Climatic Impact Assessment Program, 1975a: Propulsion effluent in the stratosphere, Monograph 2, U.S. Department of Transportation report DOT-TST-75-52, Washington, D.C.

Climatic Impact Assessment Program, 1975b: The stratosphere perturbed by propulsion effluent, Monograph 3, U.S. Department of Transportation report DOT-TST-75-53, Washington, D.C.

COMESA, 1976: The report of the committee on meteorological effects of stratospheric aircraft, Parts 1 and 2, United Kingdom Meteorological Office, Bracknell.

Comite d'Etudes sur les Consequences des Vols Stratospheriques (COVOS), 1976: Activites 1972-1976, Societe Meteorologique de France, Boulogne.

Harrison, H., 1970: Stratospheric ozone with added water vapor: Influence of high-altitude aircraft, Science, 170, 734-736.

Johnston, H. S., 1971: Reduction of stratospheric ozone by nitrogen oxide catalysts from SST exhaust, Science, 173, 517-522.

Johnston, H. S., D. E. Kinnison, and D. J. Wuebbles, 1989: Nitrogen oxides from high-altitude aircraft: An update of potential effects on ozone, J. Geophys. Res., 94, 16351-16363.

Kinnison, D. E., 1989: Effect of trace gases on global atmospheric chemical and physical processes, Ph.D. thesis, University of California, Berkeley.

Kinnison, D. E., D. J. Wuebbles, and H. S. Johnston, 1988: A study of the sensitivity of stratospheric ozone to hypersonic aircraft emissions, Proceedings of the First International Conference on Hypersonic Flight in the 21 st Century, Grand Forks, N. D., Sept. 20-23.

Kinnison, D. E., and D. J. Wuebbles, 1989: Preventing depletion of stratospheric ozoneimplications on future aircraft emissions, Air and Waste Management Association paper 89-4.7; also Lawrence Livermore National Laboratory report UCRL-99926.

National Academy of Sciences (NAS), 1975: Environmental Impact of Stratospheric Flight, Washington, D.C.

World Meteorological Organization (WMO), 1985: Atmospheric Ozone 1985: Assessment of our understanding of the processes controlling its present distribution and change, Global Ozone Research and Monitoring Project-Report No. 16.

Wuebbles, D. J., 1983: A theoretical analysis of the past variations in global atmospheric composition and temperature structure, Ph.D. thesis, University of California, Davis; also Lawrence Livermore National Laboratory report UCRL-53423.

Wuebbles, D. J., and D. E. Kinnison, 1989: A two-dimensional model study of past trends in global ozone, in Ozone in the Atmosphere, edited by R. D. Bojkov and P. Fabian, A. Deepak Publishing, Hampton, Va. 

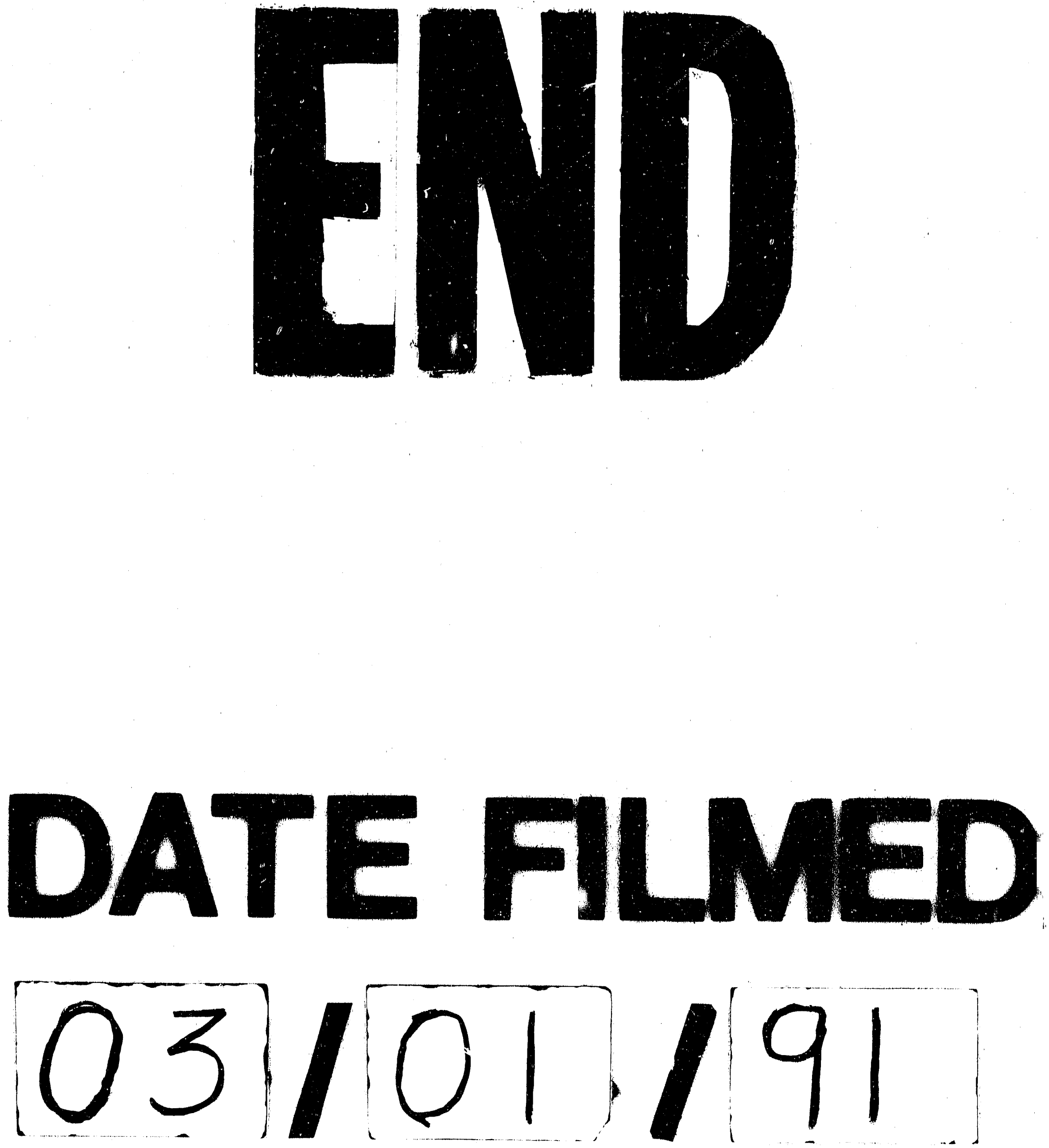
